\title{
PSYCHOSOMATIC STUDY OF SELF-EXCORIATIVE BEHAVIOR AMONG MALE ACNE PATIENTS: PRELIMINARY OBSERVATIONS
}

\author{
MADHULIKA A. GUPTA, M.D., FRCPC,
}

ADITYA K. GUPTA, M.D., FRCPC, AND NICHOLAS J. SCHORK, M.A.

\begin{abstract}
Background. Studies of the psychosomatic correlates of self-excoriative behavior in acne have involved mainly women with acne excorieé. Little is written about the psychosomatic factors that affect men with acne. Excessive self-excoriation of acne lesions is an important clinical factor because it can prolong the course of the disease and exacerbate the deeper inflammatory process with an increase in the severity of scarring.
\end{abstract}

Methods. Thirteen men (mean \pm SE: age: $22.2 \pm 1.4$ years) with mild to moderate facial acne, whose self-excoriative behavior was not severe enough to result in acne excorieé, completed a battery of self-rated questions assessing their self-excoriative behaviors, the severity of their acne, and various psychologic factors.

Results. Certain aspects of self-excoriative behavior (e.g., a tendency to pick or squeeze the acne lesions when stressed) correlated directly with depression (brief symptom inventory (BSI)) (Pearson $r=0.64, P=0.02$ ) and anxiety (BSI) (Pearson $r=0.61, P=0.03$ ) scores. The dermatologic indices of acne severity such as inflammation (Pearson $r=$ $0.82, P=0.0004$ ) and pustules (Pearson $r=0.62, P=0.03$ ) were the strongest correlates of self-excoriative behavior.

Conclusion. Self-excoriative behavior in men with acne may be exacerbated by a coexisting depressive or anxiety disorder. In contrast, women with acne excorieé have been reported to suffer from an immature personality where the cutaneous condition may serve as "an appeal for help." Men who excessively pick their acne will benefit from aggressive dermatologic therapies and should be assessed for underlying depressive and anxiety disorders.

Int J Dermatol 1994; 33:846-848

From the Department of Psychiatry, University of Michigan Medical School, Ann Arbor, Michigan, and the Division of Dermatology, Department of Medicine, Faculty of Medicine, University of Toronto, Toronto, Ontario, Canada.

Address for correspondence: Madhulika A. Gupta, M.D., Box 0704, CFOB, Department of Psychiatry, University of Michigan Hospital, 1500 East Medical Center Drive, Ann Arbor, MI 48109-0704.
Studies of psychosomatic factors affecting self-excoriative behavior in acne patients have largely involved women $^{1-5}$ with acne excorié or acne excorieé des jeunes filles. Both these groups involve patients with severely excoriated acne lesions. A wide range of psychopathologic factors have been described among patients with acne excorieé. ${ }^{1-5}$ A commonly reported finding is an immature personality lacking in effective coping mechanisms, in which the cosmetic disfigurement caused by the self-excoriated acne lesions represents an "appeal for help" by the patient. ${ }^{2-4}$ Other psychopathologies include severe body image problems, including anorexia nervosa, depression, obsessive compulsive disorder,' and a delusional disorder. ${ }^{1-4,6}$ Excessive self-excoriation of the acne lesions is an important clinical factor even among patients whose problem is not severe enough to be classified as acne excorieé because it can prolong the course of acne and increase the severity of scarring by exacerbating the deeper inflammatory process in acne. ${ }^{7}$ To our knowledge, this is the first study in which the psychosomatic factors affecting self-excoriative behavior among men with acne vulgaris have been examined systematically.

\section{Materials and Methods}

Thirteen men, all with mild to moderate facial acne vulgaris by clinical dermatologic examination (age mean $\pm \mathrm{SE}=22.2$ \pm 1.4 years), who were undergoing routine outpatient therapy for their acne, completed a battery of self-rated questions related to their self-excoriative behavior, the severity of their acne, and various other psychologic factors including body image. Informed consent was obtained from all patients and the study was approved by the University of Michigan Medical Center Institutional Review Board. All patients were unpaid volunteers.

Rating of Self-Excoriative Behavior: We developed rating scales to evaluate self-excoriative behavior in acne, based upon our clinical interviews with acne patients and the review of the literature. ${ }^{1-9}$ To our knowledge, there are no existing rating scales that assess self-excoriative behavior in acne. All items were rated on a 10 -point scale, where a rating of 1 denoted "not at all" and a rating of 10 denoted "very markedly." 
Rating of Acne Severity: All patients had mild to moderate acne vulgaris affecting the face, and, according to the dermatologic examination, the degree of excoriation was not severe enough to warrant the diagnosis of acne excoriee in any of the patients. For this study, the patients self-rated the following features of their acne on a 10-point scale: number of acne pimples; redness or inflammation of their skin due to acne; pus-filled pimples or acne pustules; scarring from the acne (pitting); and pain when they pressed the acne pimples. For the rating of number of acne pimples, a score of 1 denoted "none," and the score 10 denoted "the most you have ever had" (i.e., relative to the largest number of pimples the patient remembered having). For the remaining four items, a rating of 1 denoted "not at all" and a rating of 10 denoted "very marked." The pus-filled pimples or acne pustules were rated in relation to the remaining lesions that did not have pus. Because the ratings of acne severity were patient-rated, these relative indices reflect the subjective severity better than a report of the absolute number of pimples and pustules.

Rating of Psychologic Factors: A diverse range of psychopathologic factors have been implicated in acne excoriee. ${ }^{1-9}$ We therefore used the brief symptom inventory $(\mathrm{BSI}),{ }^{10}$ a 53 item self-report symptom inventory that screens for a wide range of psychiatric symptoms including somatization, depression, anxiety, obsessive-compulsiveness, interpersonal sensitivity, hostility, phobic anxiety, paranoid ideation, and psychoticism. Body image problems associated with eating disorders that are unrelated to the skin have been reported in acne excorieé. ${ }^{2,4}$ We therefore used the eating disorder inventory (EDI), ${ }^{11}$ a 64 -item instrument that measures eight dimensions of body image that may be affected in eating disorders, including drive for thinness, bulimia, body dissatisfaction, ineffectiveness, perfectionism, interoceptive awareness, interpersonal distrust, and maturity fears. The EDI has been previously used to assess general body image problems among acne patients. ${ }^{12,13}$

Statistical Analysis: Pearson product-moment correlations were used to examine the relationship between the various measures of self-excoriative behavior and the psychologic and dermatologic ratings.

\section{RESULTS}

Table 1 summarizes the most salient findings. The psychologic subscales that correlated significantly with the self-excoriation-related items were as follows: depression (BSI), ${ }^{10}$ a symptom dimension measuring various features of the clinical depressive syndrome, such as lack of interest and motivation, feelings of worthlessness and hopelessness; anxiety (BSI), ${ }^{10}$ a dimension composed of symptoms that are associated with high levels of manifest anxiety, for example, nervousness or shakiness and feelings of panic; somatization (BSI), ${ }^{10}$ a dimension reflecting distress arising from perceptions of bodily dysfunction; and psychoticism (BSI), ${ }^{10} \mathrm{a}$ dimension measuring certain features of a psychotic illness, such as a withdrawn and isolated lifestyle. The results (Table 1 ) indicate that for certain aspects of self-excoriative behavior (for example, item 2, Table 1), the depression (BSI) scores (Pearson $r=0.64, r^{2}=0.41$, $\mathrm{P}=0.02$ ), and the anxiety (BSI) scores (Pearson $\mathrm{r}=0.61$, $\left.r^{2}=0.37, P=0.03\right)$ explained 41 and $37 \%$, respectively, of the variance in the self-excoritive behavior. The dermatologic indices of severity, such as inflammation (Pearson $\mathrm{r}=0.82, \mathrm{r}^{2}=0.67, \mathrm{P}=0.0004$ ) and pustules (Pearson $\mathrm{r}=0.62, \mathrm{r}^{2}=0.38, \mathrm{P}=0.03$ ), explained up to 67 and $38 \%$, respectively, of the variance in the selfexcoriative behavior.

\section{DISCUSSION}

We evaluated the psychosomatic correlates of various aspects of self-excoriative behavior among young men with mild to moderate facial acne vulgaris who were attending an outpatient dermatology clinic for treatment of their acne. Psychologic factors such as depression (BSI) and anxiety (BSI) were important among patients who tended to pick their acne most of the time (item 1, Table 1) or who picked their acne when they felt stressed (item 2, Table 1). The depression (BSI) ${ }^{10}$

Table 1. Correlates* of Self-Excoriative Behavior among Men $(n=13)$ with Mild to Moderate Facial Acne Vulgaris

Clinical Feature of Mean \pm SE

Self-Excoriative Behavior Self-Excoriation

(Rated on a 10-Point Scale) Rating Psychologic Correlates

1. I tend to squeeze or pick my $4.5 \pm 1.2 \quad$ Depression $(\mathrm{BSI}): \mathrm{r}=0.60, \mathrm{P}=0.04 \quad$ Inflammation: $r=0.58, \mathrm{P}=0.03$

acne pimples most of the time.

2. I tend to squeeze or pick my $\quad 3.4 \pm 0.9 \quad$ Depression (BSI): $r=0.64, P=0.02$ acne pimples when I am under stress.

3. Once I start picking or $3.6 \pm 0.9$ Anxiety (BSI): $\mathrm{r}=0.61, \mathrm{P}=0.03$ Somatization (BSI): $r=0.66, p=0.01$ Psychoticism (BSI): $\mathrm{r}=0.57, \mathrm{P}=0.04$ squeezing my acne pimples, it is difficult for me to stop.

4. I often pick or squeeze my $\quad 4.4 \pm 0.7 \quad$ No variables acne pimples until they start to bleed.
Dermatologic (Patient Self-Rated) Correlates

Number of pimples: $\mathrm{r}=0.55, \mathrm{P}=0.04$

Inflammation: $\mathrm{r}=0.82, \mathrm{P}=0.0004$

Pustules: $r=0.62, P=0.03$

Scarring: $r=0.70, P=0.008$

Inflammation: $\mathrm{r}=0.63, \mathrm{P}=0.02$

Scarring: $r=0.67, P=0.01$

Inflammation: $\mathrm{r}=0.70, \mathrm{P}=0.005$

Pustules: $r=0.55, P=0.05$

Scarring: $r=0.69, P=0.009$

\footnotetext{
"Pearson product-moment correlation; BSI = brief symptom inventory. ${ }^{10}$
} 
and anxiety subscales $(\mathrm{BSI})^{10}$ measure clinical features of depressive and anxiety disorders. ${ }^{14}$ The correlation (item 2, Table 1) with somatization (BSI) and psychoticism (BSI) probably indicates that, when stressed, the patients who pick their acne become more somatically preoccupied and isolate themselves socially. These latter symptoms could represent features of a depressive syndrome. The direct correlation of some aspects of self-excoriative behavior with depression (BSI) and anxiety (BSI) ratings is important clinically, since both depression and anxiety can be a prominent feature of acne. ${ }^{13,15,16}$ Our findings suggest that these depressed and/or anxious acne patients are more likely to selfexcoriate their acne.

Certain findings among our patients are different from previous reports on acne excorieé. ${ }^{2,4,6}$ For example, obsessive-compulsive disorder ${ }^{6}$ is probably not an important factor among men who self-excoriate because the two items (items 3 and 4, Table 1) that measure the compulsive features of self-excoriative behavior did not correlate with any psychopathologic measures including obsessive-compulsiveness (BSI), a subscale that measures clinical features of an obsessivecompulsive disorder. ${ }^{14}$ Second, our preliminary findings suggest that serious patholgy of body image ${ }^{2,4}$ does not play a prominent role in the self-excoriative behavior among men, since none of the EDI subscales correlated with items related to self-excoriation. These findings may in part be a reflection of the fact that, whereas our patients rated their tendency to self-excoriate, their self-excoriative behavior was not severe enough to result in acne excorieé. It is also possible that among men, in comparison to women, a different group of psychologic factors are important in determining the self-excoriative behavior.

The dermatologic aspects of acne severity were the strongest correlates of self-excoriative behavior. This is in contrast to previous reports among women, ${ }^{2,4}$ such as those who have acne excorieé des jeunes filles, in whom severe self-excoriation is observed with minimal acne.

\section{CONCLUSIONS}

Our preliminary findings suggest that male acne patients who excessively self-excoriate their lesions are more likely to benefit from an assessment and appropriate management of underlying depression and anxiety disorders, in addition to receiving aggressive dermatologic therapies for their acne.

\section{REFERENCES}

1. Kenta A, Drummond LM. Acne excorieé-a case report of treatment using habit reversal. Clin Exp Dermatol 1989; 14:163-164.

2. Sneddon J, Sneddon I. Acne excorieé: a protective device. Clin Exp Dermatol 1983; 8:65-68.

3. Spraker MK. Cutaneous artifactual disease: an appeal for help. Pediatr Clin North Am 1983; 30:659-668.

4. Sneddon J, Sneddon I. Acne excorieé: a protective device. Br J Dermatol 1981; 105(Suppl 19):29.

5. Wrong NM. Excoriated acne of young females. Arch Dermatol Syphilol 1954; 70:576-582.

6. Koo JYM, Smith LL. Psychologic aspects of acne. Pediatr Dermatol 1991; 8:185-188.

7. Tolman EL. Acne and acneiform dermatoses. In: Moschella SL, Hurley HJ, eds. Dermatology. Vol. 2, 3rd Ed. Philadelphia: WB Saunders, 1992:1477.

8. Strauss JS. Sebaceous glands. In: Fitzpatrick TB, Eisen AZ, Wolff $\mathrm{K}$, et al, eds. Dermatology in general medicine. New York: McGraw-Hill, 1987:666.

9. Ebling FJG, Cunliffe WJ. Disorders of the sebaceous glands. In: Champion RH, Burton JL, Ebling FJG, eds. Textbook of dermatology. Vol 3. 5th Ed. Oxford: Blackwell Scientific, 1992:1699.

10. Derogatis LR, SPencer PM. The brief symptom inventory (BSI). Administration, scoring, and procedures. Manual-L. Baltimore: Johns Hopkins University, 1982.

11. Garner DM, Olmsted MA, Polivy J. Development and validation of a multidimensional eating disorder inventory of anorexia nervosa and bulimia. Int J Eating Disorders $1983 ; 2: 15-34$.

12. Gupta MA, Gupta AK, Ellis CN, Voorhees JJ. Bulimia nervosa and acne may be related: a case report. Can J Psychiatry 1992; 37:58-61.

13. Gupta MA, Gupta AK, Schork NJ, et al. Psychiatric aspects of the treatment of mild to moderate facial acne: some preliminary observations. Int J Dermatol 1990; 29:719-721.

14. American Psychiatric Association. Diagnostic and statistical manual of mental disorders. 3rd Ed. Washington, DC: American Psychiatric Press, 1987.

15. Wu SF, Kinder BN, Trunnell TN, Fulton JE. Role of anxiety and anger in acne patients: a relation with the severity of the disorder. J Am Acad Dermatol 1988; 18: 325-333.

16. Rubinow DR, Peck GL, Squillace KM, Gantt GG. Reduced anxiety and depression in cystic acne patients after successful treatment with oral isotretinoin. J Am Acad Dermatol 1987; 17:25-32. 
This document is a scanned copy of a printed document. No warranty is given about the accuracy of the copy. Users should refer to the original published version of the material. 